Trabajos y Comunicaciones, 2da. Época, No 47, e057, enero-junio 2018. ISSN 2346-8971

Universidad Nacional de La Plata.

Facultad de Humanidades y Ciencias de la Educación.

Departamento de Historia

\title{
Los muchachos peronistas antijudíos. A propósito del antisemitismo en el movimiento peronista
}

\author{
The anti-Jewish Peronist boys. On the subject of anti-Semitism in \\ the Peronist movement
}

\author{
Juan Luis Besoky * \\ * CONICET- Universidad Nacional de La Plata - Facultad de Humanidades y Ciencias de la \\ Educación, Argentina \\ jcbesoky@fahce.unlp.edu.ar
}

\section{PALABRAS CLAVE}

Antisemitismo

Peronismo

Nacionalismo

Derecha

\section{KEYWORDS}

Antisemitism

Peronism

Nationalism

Right Wing

\section{RESUMEN}

El propósito de este artículo es rastrear y analizar el discurso antisemita de un sector de derecha del peronismo. Para el análisis de este discurso se utilizan como fuentes la prensa partidaria, volantes y declaraciones públicas de intelectuales, militantes y organizaciones. Su análisis nos permite complejizar y matizar la visión del peronismo ya que si bien es cierto que desde el gobierno peronista se fomentaba la tolerancia religiosa y se incluía a varias personas de la colectividad judía en cargos del gobierno, otras organizaciones provenientes del nacionalismo de derecha mantuvieron y difundieron de manera constante su antisemitsmo.

\section{ABSTRACT}

The purpose of this article is to trace and analyze the anti-Semitic discourse of a right-wing sector of Peronism. For the analysis of this discourse are used as sources the party press, leaflets and public declarations of intellectuals, militants and organizations. Their analysis allows us to complexify and nuance the vision of Peronism because while it is true that the Peronist government promoted religious tolerance and included several people from the Jewish community in government positions, other organizations from right-wing nationalism consistently maintained and disseminated their antisemitsm. 


\section{Introducción}

En un libro de reciente aparición titulado Los muchachos peronistas judíos. Los argentinos judíos y el apoyo al Justicialismo, escrito por el historiador israelí Raanan Rein (2016), se busca demostrar el fuerte rechazo a cualquier tipo de discriminación por parte del presidente Perón. Confrontando con varios mitos que se han construido sobre el carácter fascista y antisemita del peronismo, lo que explicaría la presunta ausencia de judíos dentro del movimiento, Rein establece una serie de postulados. En primer lugar señala que Perón no era nazi ni fascista y que el peronismo se nutrió de una mezcla de influencias políticas e ideológicas siendo más adecuada la categoría de populismo. A esto agrega la ausencia de actitudes antisemitas en Perón y en Eva Perón e incluso en el mismo movimiento. Por último advierte que fueron numerosos los judíos que apoyaron al naciente peronismo desde las primeras horas y que muchos de ellos se expresaron a través de la Organización Israelita Argentina (OIT). Rein concluye “... Perón fue el primer mandatario argentino que legitimó el mosaico de identidades de distintos grupos étnicos en su país. Él no vio ninguna incompatibilidad entre ser un buen argentino, ser un buen judío, y dar apoyo al sionismo o al Estado de Israel.” (Rein, 2015: 13).

A lo largo del libro, Rein se encarga de destacar la inmigración judía a la Argentina y la actitud tolerante y democrática de Perón para con esa colectividad, a la cual no negó la identidad étnica, sino que más bien aceptó como una parte integral de la nacionalidad. Rein destaca la creación de una sección judía del Partido Peronista: la OIT, de la cual saldría nombrado como primer embajador argentino en Israel, su dirigente Pablo Manguel. Por último, el autor analiza la presencia de importantes figuras de la comunidad judía que apoyaron el peronismo desde los medios de comunicación como César Tiempo y Jaime Yankelevich y desde el sector sindical y empresarial como Ángel Perelman y José Ber Gelbard.

Si bien todos estos hechos son ciertos, no hay que olvidar la presencia de figuras y organizaciones que mantuvieron desde el peronismo, un marcado discurso antisemita. Rein es consciente de su existencia por lo cual al final del libro advierte: "Las expresiones antisemitas de alguna gente de la derecha peronista y de varias figuras de la CGT han contribuido a crear una imagen exagerada y distorsionada de un peronismo antijudío, que aún persiste y que no diferencia entre las primeras dos presidencias de Perón y la tercera, que se desarrolló en un contexto nacional e internacional completamente distinto”. (Rein, 2015a: 375)

El propósito de este artículo es rastrear y analizar el discurso antisemita de un sector de derecha del peronismo que, si bien fue minoritario, no debe ser dejado de lado. Entiendo a la derecha peronista como una serie organizaciones, militantes, intelectuales y publicaciones que actuaron en el interior y en los márgenes del movimiento peronista. La expresión "nacional justicialismo” o "peronismo ortodoxo" también definió a estas agrupaciones, aunque en forma más general designa una cultura política, con la que se referenciaron dichas organizaciones y en la que fueron inscriptos por el mismo Perón, por otras corrientes del peronismo y por otras ajenas al mismo. Su análisis nos permitirá complejizar y matizar la visión del peronismo, no para cuestionar lo sostenido por Rein pero sí para enriquecer la compresión del fenómeno peronista. 


\section{La cuestión judía y la conspiración judeo masónica}

Sostiene Lvovich (2003: 19) que la Argentina es el único país latinoamericano donde se logró instalar una “cuestión judía”, es decir, la concepción de la presencia judía como un problema para la nación. Fueron justamente los nacionalistas argentinos quienes más énfasis pusieron en esta cuestión a través de sus discursos y prácticas. Si bien la representación del judío como un otro o como un enemigo no estuvo ausente en la tradición liberal, en el campo nacionalista el antisemitismo adquirió una importancia central, se combinó con una mirada conspirativa, y fomentó mayores prácticas de discriminación y violencia.

Lvovich (2003: 27) advierte que junto al antisemitismo tradicional, consistente en la aceptación pasiva de difundidos estereotipos sobre los judíos, y al ideológico, que adquiere una forma mucho más precisa y elaborada, ha de señalarse una formación discursiva intermedia: la mitología sobre la

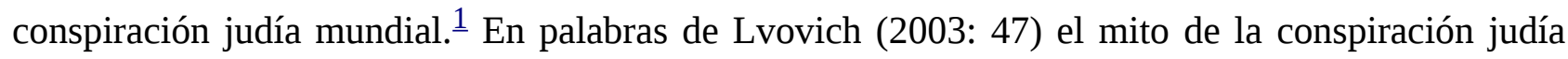
mundial supone la existencia “de un gobierno secreto israelita que, mediante una red mundial de organizaciones camufladas, controla los partidos políticos y gobiernos, la prensa y la opinión pública, los bancos y la economía”. Tempranamente este tipo de mito se combinó con la denuncia de que el comunismo era un instrumento del judaísmo. Para el militante nacionalista Bonifacio Lastra:

"Y así, mientras eran los judíos los que dominaban la riqueza de los países y mientras su influencia se hacía sentir en los gobiernos -cuando no eran los mismos hombres de Israel los que gobernaban- y mientras daban al arte y a la belleza un sentido materialista y perverso, ¡cosa extraña!, eran también judíos quienes predicaban el comunismo y la revolución social y enseñaban a las masas sumidas en el sufrimiento que su explotación iba a cesar si odiaban a Dios y negaban a la Patria” (Lastra, 1944: 153).

Esta contradicción de explotar a los hombres e incitarlos al mismo tiempo a la rebelión se debía al "plan de la judería":

“Adueñada de la riqueza, sometidos a su yugo los gobiernos, corrompidas las costumbres y lanzadas unas clases sociales contra otras, fácil será la destrucción de las naciones cristianas para implantar el imperio universal judío y esperar después, de acuerdo a sus profecías malditas, que llegue su Mesías...” (Lastra, 1944)

Posteriormente también se sumó a la masonería y al liberalismo dentro de un esquema conspirativo más global. Tal como señalaba el nacionalista Bruno Jacovella en el periódico Crisol:

"Es Israel quien mueve los hilos no sólo de la Masonería, cuyo fin con el liberalismo es la disolución de la sociedad cristiana, sino también del comunismo, su etapa complementaria, cuyo fin es la destrucción de la misma, ya debilitada por aquél, y la instauración sobre sus ruinas del reino del Anticristo”. Citado por Lvovich (2003: 325).

Buchrucker (1987) ha indicado que uno de los aspectos originales del conspiracionismo argentino es la curiosa síntesis entre la denuncia tradicional del complot judío y el anti-imperialismo de tintes izquierdistas. Justamente una de las figuras que más contribuyó a ello y que influyó en la 
organización nacionalista Alianza Libertadora Nacionalista fue Ramón Doll quien poseía una antigua militancia en el socialismo e incorporó su antiimperialismo de vieja data al nacionalismo buscando dotarlo de un contenido revolucionario moderno. En palabras de Lvovich "Doll veía en los judíos la síntesis perfecta del enemigo, ya que los concebía a la vez como el corazón mismo del imperialismo inglés y como la figura inconfundible del antagonista infiltrado en la vida nacional para obstaculizarla.” (Lvovich, 2003: 337).

Dentro del nacionalismo esta conspiración también era denunciada en tanto afectaba la integridad territorial de la nación. Bohoslavsky (2009) ha demostrado como preocupación recurrente de los nacionalistas argentinos las amenazas externas sobre la Patagonia argentina propiciadas por ingleses (quienes ya controlaban las Islas Malvinas) y chilenos, en muchos casos residiendo en la zona. A esta amenaza se sumaba la acción conspirativa del sionismo y del comunismo. Esta preocupación por la mutilación del territorio nacional tenía que ver con que "Si la nación es el territorio, cualquier reducción o variación en el tamaño del espacio dominado aparece, fatalmente, como una amenaza directa a la nación”. (Bohoslavsky, 2009)

Como discurso principal del imaginario nacionalista, el antisemitismo también fue parte de la derecha peronista. El crecimiento de este sector del peronismo se nutrió tanto del desgajamiento de militantes procedentes de diversas corrientes del nacionalismo de derecha argentino: Alianza Libertadora Nacionalista y Movimiento Nacionalista Tacuara, que reinterpretaron la naturaleza y posibilidades ofrecidas por el peronismo; así como fue el resultado de la evolución de agrupaciones y figuras que, provenientes del peronismo, incorporaron algunas concepciones del nacionalismo de derecha y resignificaron el proyecto del Movimiento y el rol de su líder. Esta cultura política se caracterizó por la combinación de elementos provenientes de la cultura nacionalista y de otros de origen peronista, siendo sus principales rasgos el énfasis en el nacionalismo, en el revisionismo histórico -con especial hincapié en la figura de Rosas-, un marcado antisemitismo y anticomunismo y cierta preferencia por la acción directa y violenta en su enfrentamiento con la izquierda. (Besoky, 2013)

Justamente una de las primeras organizaciones del nacionalismo argentino que adhirió al peronismo fue la Alianza Libertadora Nacionalista (ALN). $\underline{2}$ Esta organización conducida por Juan Queraltóera notoriamente antisemita y rechazaba por igual el comunismo y el capitalismo promoviendo la instauración de un Estado corporativo autoritario. La intención era ganar la calle y enfrentar a los enemigos en el lugar que se encontraran. Según señala Beraza (2005) reemplazaban la dialéctica de los grandes discursos por la de puños y pistolas, incorporaban el trato de "camarada” y buscaban convertir a los jóvenes trabajadores al nacionalismo. Eran frecuentes sus enfrentamientos y ataques a militantes e instituciones judías y de izquierda.

Para la ALN, la cuestión judía era central dentro de sus preocupaciones. En los "Postulados de nuestra lucha” de 1940 no coma denunciaban el problema judío como uno de los más graves y proponían “cerrar en absoluto” la entrada de judíos al país y proceder con medidas apropiadas para frenar “su perniciosa influencia en el gobierno, en la economía y en la cultura”.

Por su parte Senkman (2004: 102) dice que la violenta retórica judeofóbica de la ALN no era novedad en el campo nacionalista, en cambio sí lo era la interpelación racista en sus movilizaciones 
callejeras y concentraciones públicas. En este sentido era original "su intento de secularizar la retórica nacionalista judeofóbica, al denunciar a los judíos por la supuesta conexión con el imperialismo británico, además del pretendido acaparamiento de la economía, los espectáculos y la moderna cultura urbana".

El discurso que pronunció uno de los referentes de la ALN Bonifacio Lastra en el acto nacionalista del $1^{\circ}$ de mayo de 1943, y que fuera compilado posteriormente bajo el título de "El judaísmo, enemigo de la patria y de los trabajadores”, acusaba al judaísmo de haber desencadenado sobre el mundo "toda una manera de pensar y de sentir sensualista, anti-heroica y anti-espiritual". Además de ser los dueños de la banca internacional, desde los tiempos de Rotschild, buscaban controlar las economías y condicionar la producción a favor de su lucro personal. El periódico de la ALN denominado Alianza, en el número del 12 de febrero de 1945, se mostraba preocupado por la numerosa presencia judía en Argentina:

"Muchos de los males argentinos de nuestros días se registran agravados en la provincia de Entre Ríos. Quizá la principal causa determinante sea la presencia judía en sus campos y ciudades. Es tremenda la invasión que ha sufrido la criollísima tierra entrerriana. A través de las generaciones, se mantiene, en los judíos el espíritu de su raza, de sus hábitos, de sus aspiraciones históricas, que los convierten en un quiste inasimilable y hostil dentro de la comunidad argentina”.

Luego de señalar la existencia de localidades en la provincia donde la presencia judía llegaba al 90\% el periódico hacía en su última página una reseña del libelo antisemita Los Protocolos de Los sabios de Zion y las aspiraciones de Israel para dominar el mundo. $\underline{3}$ En el número siguiente continuaba con este tipo de reseñas y citaba un extenso fragmento de la novela antisemita La Bolsa de Julián Martel, seudónimo de José María Miró y que fuera publicada originalmente en 1891 en el diario La Nación. Para los redactores de Alianza en esta excelente novela costumbrista se reflejaban los estereotipos del "político venal, la mujer mundana, el abogado sin escrúpulos y el judío aventurero" contra los que el autor levantaba su dedo acusador. Además sostenía el periódico "no dejará de constituir una sorpresa para muchas mentalidades simples, que a pie juntillas consideran que el anti-semitismo se debe a los 'nazis'. Se debe a los semitas, como la vacuna se debe a la viruela.". .4

No solamente en la prensa es posible observar el discurso antisemita de la ALN sino también en acciones directas. Siguiendo el lema de José Antonio Primo de Rivera, fundador de la Falange, la organización promovió un nuevo estilo político tendiente a disputarle a la izquierda el lugar que ocupaba en las calles. Eran frecuentes las refriegas callejeras y los atentados o amenazas contra locales comunistas y también contra personas e instituciones judías. Entre estas se cuenta en agosto de 1942 la agresión contra el escritor norteamericano y judío Waldo Frank, de intensa militancia antifascista, por parte de jóvenes nacionalistas de la AJN. En sus memorias José Luis de Imaz recuerda que el patio del local de la Alianza parecía la antesala de un hospital, donde "el que no lucía un parche en la ceja tenía un brazo entablillado, o algún hematoma en la cara o los brazos. Y todos contaban a grito en cuello, y sin escucharse mayormente, historias de épicos combates contra 'bolches’ muchos más numerosos'” (Citado por Beraza, 2005: 37). 
Incluso la misma jornada del 17 y 18 de octubre de 1945 incluyó varios hechos antisemitas sobre los cuales (Lvovich, 2001) ha llamado la atención, con el apedreo a templos y gritos tales como “mueran los judíos”. Esto conllevó a que el presidente de la DAIA, Moisés Goldman, escribiera una nota de protesta al presidente Edelmiro J. Farrell, en Mundo Israelita, el 27 de octubre de 1945:

“...las agresiones de palabra y de hecho de que ha sido objeto nuestra colectividad como tal el día 18 del corriente en la Capital Federal y varias localidades del interior de la República, particularmente en la ciudad de Córdoba. En Buenos Aires, desde las primeras horas de la mañana del día señalado grupos que integraban manifestaciones recorrieron las calles en actitud provocativa y a los gritos de 'mueran los judíos' sembraron impunemente la intranquilidad en los sectores judíos de la Capital. (...) El Templo de la calle Paso 423 fue apedreado. (...) La pedrea se hizo extensiva a varios establecimientos judíos. En algunos frentes se inscribieron leyendas injuriosas e incitando a la matanza” (Citado por Lvovich, 2001: 63).

Estos desmanes atribuidos a sectores nacionalistas fueron repudiados por el diario peronista $\mathrm{La}$ Época, el cual acusaba a la infiltración en las columnas obreras de elementos "notoriamente nazifascistas (...) que las democracias han derrotado y aplastado en su tierra de origen”. $\underline{5}$ En la explicación de Lvovich (2011: 66):

“...el "olvido" peronista de los acontecimientos antisemitas en el seno de las jornadas del 17 y 18 de octubre se debió a una serie de motivos relacionados: tales eventos, como los otros hechos de violencia, no contribuían a la conformación de una imagen armónica y legítima de aquellas jornadas; su rememoración -más allá de las voces oficiales del peronismo que en su momento se hicieron escuchar para condenar con severidad tales disturbios- podía contribuir a conformar la imagen de un Movimiento en cuya génesis se encontraran contenidos racistas; y por último, debido a que tales eventos resultaron absolutamente marginales desde la perspectiva de la totalidad de la movilización popular.”

También durante el año 1947 recrudeció la actividad antisemita por parte de la ALN. Furman (2014: 243-244) señala que en enero diversos barrios porteños aparecieron pintados con la inscripción “Haga patria, mate a un judío” firmada por la ALN. En los meses siguientes se registraron bombas contra el domicilio de un vecino judío cercano a la Escuela Israelita Scholem Aleijem, la sinagoga de la calle Lavalle 2499 en el barrio de Once y en la Asociación Israelita de Culto y Beneficencia de Belgrano entre otros.

Además de la ALN existían otras figuras dentro del peronismo que compartían el discurso profascista y antisemita y que contaron con el apoyo de Perón, por lo menos en sus primeros años. Este fue el caso del ministro del interior general Luis Perlinger, del jefe de Policía Federal, General Juan F. Velazco, el director de la Biblioteca NacionalGustavo Adolfo Martínez Zuviría y el director del Departamento de Migraciones, Dr. Santiago Peralta, todos provenientes de la administración Farrell y finalmente desplazados, a excepción de Zuviría, por Perón en 1947.

El caso de Peralta es el más elocuente respecto a la presencia de funcionarios antisemitas en el gobierno nacional. $\underline{6}$ Peralta, quien era un antropólogo recibido en la Facultad de Filosofía y que 
había estudiado “antropología aplicada” en Alemania en 1932, había publicado libros discriminatorios como La acción del pueblo judío en la Argentina (1943). Según advierte Rein (2015a: 83): “este libro es un ataque contra los avaros y astutos "señores del mundo", los comerciantes y usureros que entraron también a la Argentina desde la época colonial”. Para 1946 Peralta había publicado otro libro titulado La acción del pueblo árabe en Argentina, donde comparaba los beneficios de fomentar la inmigración árabe frente a la judía. Desde su puesto de Director de Migraciones, al que había llegado en 1945 nombrado por Farell y confirmado luego de la asunción de Perón, Peralta se encargó de bloquear sistemáticamente el arribo de refugiados judíos hasta que un escándalo internacional lo obligó a renunciar. Al respecto señala Goñi (2009: 78):

"La interceptación de un comunicado secreto dando instrucciones a los cónsules argentinos para que negaran visados a los judíos se convirtió en tema de debate en la ONU. Luego, a un hombre de negocios judío que se reunió con Peralta para pedirle un permiso de desembarco para su hermano se les respondió que hiciera las maletas y se fuera mientras él y la comunidad judía estuviera a tiempo. Los grupos de rescate y de ayuda a los judíos presentaron una protesta especial. Finalmente, en junio de 1947, Perón cedió a las presiones y Peralta fue cesado”.

Otra figura importante de la prédica antisemita que adhirió tempranamente al peronismo fue 1 presbítero Virgilio Filippo, quien se destacó como uno de los más importantes divulgadores del antisemitismo en la década de 1930 (Lvovich, 2003: 417). Si bien carecía de las cualidades de intelectuales de Franceschi y Castellani o de la erudición teológica de Meinvielle, su importancia residió en "el rol de publicista del ideario antiliberal, anticomunista y antisemita a través del uso de la radio".

De esta manera, Filippo aprovechaba todo el material antisemita que caía en sus manos para construir un texto virulentamente judeofóbico, en el que criticaba desde el carácter anticristiano del judaísmo hasta las teorías “judías” de Freud, Einstein y Lombroso, pasando por la denuncia de las escuelas judías comunistas. Filippo en su obra Los Judíos avalaba las teorías del complot: “Constatad cuáles son los grandes barrios judíos, e inquirid cuáles son los resultados de las elecciones. Donde hay más judíos hay triunfo socialista revolucionario” (Buchrucker, 1987: 148. En palabras de Lvovich:

"Filippo reunía en su prédica toda clase de imputaciones. En ellas se conjugaban el deicidio y las referencias a San Agustín y San Mateo con la apelación a los textos antijudíos de Sarmiento y a las denuncias del comisario Alsogaray sobre la trata de blancas, sin dejar de lado las obras de Degreff ni las citas de Santa Fe judaizada. (...) no dejaba de repetir todo tipo de dislates sobre el Talmud ni de demostrar su nostalgia por las épocas de vigencia de la Inquisición, completándose el libro con una serie de poesías de su autoría referidas a la avaricia, el racismo y la usura de los judíos”. (2003: 417)

Buchrucker (1987) advierte que terminada la segunda guerra mundial muchos escritores antisemitas quedaban como aliados intelectuales de los técnicos nacionalsocialistas del genocidio, por lo cual “casi todo el mundo buscó poner distancia de conexiones tan comprometedoras”. De esta manera 
notorios antisemitas como Enrique Osés y Luis Silveyra desaparecieron en el anonimato mientras que el padre Filippo, ya convertido en diputado peronista en 1948, “dejó de insistir con el tema de los judíos, concentrándose más bien en la lucha contra la masonería, en la cual tampoco obtuvo el apoyo de los demás parlamentarios peronistas.”. El propio Filippo dirá, "La verdad es que nuestra propia bancada... está contaminada de marxismo, masonería, liberalismo, socialismo e izquierdismo” (Citado en Rock, 1993: 182).

Todo este accionar antisemita contrasta de todas formas con la realidad de un gobierno que había permitido la llegada numerosos judíos a la burocracia estatal logrando cargos más importantes que los alcanzados anteriormente. Como ha señalado Rein (2015a: 11) fueron numerosos los judíos que apoyaron al peronismo desde la primera hora. "Su número creció a medida que el régimen se afianzaba en el poder, y a raíz de la reelección de Perón en noviembre de 1951”. A los casos de figuras destacadas como el dirigente sindical Ángel Perelman, el empresario Jaime Yankelevich, el escritor César Tiempo, el subsecretario del Ministerio de Relaciones Interiores Abraham Krislavin y tantos otros mencionados por (Rein, 2015a) se sumaba el apoyo dado al peronismo por la Organización Israelita Argentina (OIA). Ya en vísperas de las elecciones de 1948 la organización había sacado una solicitada convocando a los judíos argentinos a votar por los candidatos peronistas:

“...al amparo de los derechos que asegura la Revolución justicialista la colectividad judía, que desarrolla sus actividades sin trabas, practicando el culto de sus mayores, asociándose sin obstáculos, ejerciendo el comercio y la industria empleándose en cualquier tarea lícita y honorable, interviniendo en todas las profesiones, estudiando en todas las escuelas y universidades, formando, en fin, parte misma del país en lo que tiene de más bueno y fecundo, respetada y considerada por todos y, en primer término, por el Excmo. Señor Presidente la Nación Gral. Juan D. Perón”. $\underline{7}$

Paradójicamente uno de los candidatos a diputado presentes en las listas peronistas por las cuales la OIA llamaba a votar, era el sacerdote antisemita Virgilio Filippo. Y si bien, como señalamos antes, Filippo acalló sus críticas al judaísmo, no lo hizo la ALN cuya prédica antisemita continuó vigente en varios artículos de Alianza. En 1951, cuando la ALN salió a denunciar el fallido intento de golpe de Estado del 28 de setiembre de 1951 contra Perón, el editorial explicaba el alzamiento como “pestilencia semita” alentada por "la zarpa del capitalismo judío de Wall Street”. En el número 103 del 15 de agosto de 1951, Alianza traía un artículo sobre la preponderancia semita en la cinematografía de Estados Unidos y otro con el título “¿No serán jettatores los buenos judíos?” en el cual con clave irónica se preguntaban por el fracaso de los partidos políticos argentinos: "Porque cada vez que los buenos, pacíficos y trabajadores judíos (la laboriosa colectividad) ha prestado apoyo a un partido político, ese partido ha "sonado" estrepitosamente en la primera de cambios." Como ejemplos mencionan el caso del Partido Socialista y luego del Socialismo Independiente. En cambio, respecto al peronismo sostenían, que este triunfó porque “en el año 1945 toda la honrada y simpática colectividad hebrea estaba en contra del General Perón. En toda la campaña no entró un judío a un comité peronista, ni por descuido.” Frente al aparente maleficio de la colectividad judía la ALN se mostraba preocupada: 
elecciones, gracias al voto contrario de los judíos, no correrá ahora el riesgo de perderla al darse el juego al revés? ¿No será mejor hacer algo para que se larguen en contra? (...) Si ayer ganamos sin la colectividad, con más razón lo podemos hacer hoy.”. 8

Fue recién con la llegada de Guillermo Patricio Kelly a la jefatura de la ALN en abril de 1953, en reemplazo de Queraltó, que la ALN se desprendió de todo el discurso antisemita en coincidencia con la total peronización de la organización. Así lo destacaba Kelly en un artículo del periódico:

\begin{abstract}
"Nosotros no estamos con Perón como Nazis, Fascistas, Falangistas o Antisemitas, sino lisa y llanamente como hijos de una revolución que nació el 4 de Junio y se bautizó el 17 de Octubre en la Rep. Argentina. (...) Querer destruir Alianza es pretender volver al Nazismo, Fascismo, Falangismo o a "Mueran los judíos... Muera todo..." a verdad que esto es imposible (...) El Nacionalismo es el pueblo que acompaña a Perón... (...) He aquí donde radica nuestro Nacionalismo, en el deseo de la Patria misma. Ni izquierdas ni derechas; sencillamente hijos de ella realizando la mejor de las revoluciones que es la de los espíritus trabajando y no politiqueando y defendiéndola contra las injusticias para poder concretar lo mucho contenido en nuestros principios de Dios, Patria y Hogar”. $\underline{9}$
\end{abstract}

Señala Senkman (2004: 106) que la legitimación de la convivencia entre judíos y cristianos en la prensa de la ALN, totalmente peronizada es posible leerla en Alianza ( $\mathrm{N}^{\circ}$. 20, 1ra quincena julio 1954) en el artículo "Católicos-Judíos", a propósito de la visita del Nuncio Apostólico a la embajada de Israel, que le confirma a su director que el peronismo "se inspira en la doctrina de la Iglesia, manteniendo relaciones con todos los pueblos y razas del mundo sin hacer cuestión de colores, de piel, religión, raza".

Algo similar sucede con el periódico Liberación, donde escribían varios aliancistas y que a partir de octubre de 1953 propugnó la conciliación en el orden obrero-sindical, social, económico y cultural de la Nueva Argentina inclusiva y populista. También se registró la ausencia de referencias, tan comunes en los números anteriores, al mito conspirativo judeo-masón-marxista. En este sentido es de destacar, como bien señala Senkman (2004) la indulgencia y ambigüedades de Perón que:

“...estimularon durante varios años a la ALN a jugar la carta antisemita como mito movilizador populista cuando el peronismo necesitaba mostrar su capacidad disruptiva en la escena política local, separada en dos bloques implacablemente enemigos. Prueba de ello es que, luego de la bochornosa derrota electoral de la ALN en 1946, los espiantavotos" aliancistas (sic) fueron tolerados por el régimen para operar como fuerza de choque autónoma en las universidades y sindicatos controlados por la oposición de izquierda”.

Sin embargo, en el resto del campo nacionalista e incluso posteriormente para sectores del peronismo de derecha, la influencia del judaísmo y la masonería siguió siendo utilizada para explicar el conflicto peronista con la Iglesia Católica a partir de 1954. (Buchrucker, 1987: 355) advierte que se corrió el rumor entre los nacionalistas que la influencia de los judíos en el Ministerio del Interior (Abraham Krislavin era subsecretario allí), combinada con la masonería (dentro de la cual incluían al vicepresidente Alberto Teisaire), eran dos de los factores responsables dela nueva postura laicista o anticlerical del gobierno. 


\section{Judaísmo y antisionismo en la década de 1960}

Luego de la caída del peronismo el judaísmo siguió siendo, al igual que en las décadas anteriores, un motivo de preocupación y denuncia para el nacionalismo de derecha. Los años sesenta, y especialmente después del secuestro de Adolf Eichmann en Argentina por un comando israelí, fueron testigos de un virulento rebrote antisemita, impulsado sobre todo por las organizaciones derivadas del Movimiento Nacionalista Tacuara $\frac{10}{}$ como el Movimiento Nueva Argentina (MNA). Esta organización que se identifica como peronista y nacionalista respondía a una entrevista en los siguientes términos:

“-¿Qué es para ustedes el Judaísmo?

- Una colectividad que se ha convertido en burguesía mercantil y oligarquía financiera como forma de ejercer dominio político sobre los demás pueblos por medio del dinero. Nuestro país es hoy prueba de ello. Para ellos no hay hambre, no hay desocupación, no hay desnutrición ni analfabetismo; eso lo dejan para los hijos del país. Esa es su respuesta a la política de puertas abiertas y mano tendida con que se los recibió. A ello contestaron con una cerrada negativa a integrarse con el resto de la población, aislándose, creando sus centros, sus clubes, sus colegios, sus templos. Con el objeto de separarse de los demás como si estuvieran en territorio enemigo, y preservar así su fanatismo racial y religioso, aptitud que favorecida por nuestro liberalismo gobernante, les permitió obtener el control de nuestras finanzas, nuestro comercio, nuestra prensa, nuestras universidades, casi diríamos de nuestro país. Todo esto es verdad aunque esté prohibido decirlo.”1ㅡ

Por esos años, también se hace presente el discurso antisemita en una serie de publicaciones de la resistencia peronista que pueden ser ubicadas a la derecha del movimiento. Estas publicaciones aparecen a partir de 1963 como una respuesta a los sectores de izquierda del peronismo que se empezaban a nuclear en el periódico Compañero. Estas publicaciones, que no respondían a alguna agrupación política, eran sostenidas por militantes peronistas, muchos de los cuales provenían del nacionalismo de derecha. El primer caso fue el semanario Huella, aparecido en La Plata en septiembre de 1963. Este semanario era dirigido por Pedro Michelini, $\underline{12}$ un abogado laboralista platense defensor de presos sindicales, acompañado por Alberto Baldrich. 13 Escribían allí Elías Giménez Vega, Carlos Steffens Soler, José Julio Jáuregui, José María Rosa, Emilio Pasini Costadoat, Julio C. González y Alfredo Gómez Morales, entre otros. Se sostuvo con los ingresos propios de Michelini hasta que por cuestiones económicas debió cerrarlo. Sacó un total de 34 números entre el 10 de septiembre de 1963 y el 2 de octubre de 1964. Empezó saliendo todos los martes para luego hacerlo quincenalmente, siempre de manera gratuita. Según Carman (2015: 337) estaba "cercano a sectores de la juventud Peronista de derecha que favorecieron el acercamiento con el Movimiento Nacionalista Tacuara. Ataca a Israel y propone acciones conjuntas con los árabes.”. Siguiendo esta línea aparece una entrevista de Raúl Jassén al presidente de Argelia Ahmed Ben Bela (Nº, 22/10/63). En la contratapa del No24 (31/3/64), se distingue el artículo "La dominación Anglo-Judía” y en el Nº30 (23/6/1964) dirán "Esta es la opción: PERÓN O COMUNISMO Y CAOS”.

Otra publicación de la derecha peronista era Patria Libre dirigida por Susana Valle, hija del general 
Juan J. Valle fusilado en 1956, y el periodista Fernando García Della Costa, antiguo nacionalista miembro de la ALN. La publicación poseía 16 páginas y tenía un tono más serio en los artículos de las secciones política y economía. Sacó un total de 12 números entre el 14 de marzo de 1963 y el 17 de marzo de 1964, saliendo los primeros 6 en vísperas de las elecciones presidenciales. Fue financiada con el dinero que ganó García Della Costa en una rifa del Club Boca Juniors y dejó de salir cuando este dinero se acabó. Escribieron allí Fermín Chávez, Adolfo Pérez Portillo, Anselmo Pozzi, César Berutti, Rogelio Giordano, José María Rosa, Alberto Baldrich, Enrique Pavón Pereyra, Salvador Nielsen, José Luis Muñoz Aspiru, Oscar Denovi y Juan Carlos Cornejo Linares, entre otros.

Según Senkman (1986: 54), los intentos por vincular antisionismo, anticomunismo y antisemitismo por parte de círculos derechistas del peronismo están documentados en ambas publicaciones. Huella publicó el 31 de marzo de 1964 una nota de Raúl Jassén y otra de Andrés Framini en las que acusaban a los sionistas y comunistas de haber robado los legajos de los asesinos de Rosario (haciendo referencia al enfrentamiento entre tacuaristas y comunistas en Rosario) y acusaba a la prensa del país de recibir órdenes desde afuera, redactadas en inglés, chino o hebreo. También advertían a los trabajadores, peones y obreros "que no hay solución para sus problemas mientras sigan dominando esas fuerzas (el sionismo racista y militarista) en nuestros centros vitales políticos y económicos” (Senkman, 1986: 54).

Por otro lado, otra publicación era Patria Bárbara, dirigida por Raúl Jassén $\frac{14}{}$ y financiada por el empresario peronista Jorge Antonio, salió a la luz el 4 de octubre de 1964 y publicó 14 números hasta 1965. Tuvo una segunda época a partir de 1973. Se definía como una "Publicación independiente de Información Nacional-Justicialista”. Como redactores solían aparecer Jaime Lemos, Alberto E. Asseff, Ignacio B. Anzoátegui, Juan Carlos Cornejo Linares, Alberto Baldrich y Gabriel Ruiz de los Llanos. En la revista eran frecuentes las críticas al judaísmo, el sionismo, el comunismo y "la infiltración en el Movimiento".

Posteriormente se editó Retorno, cuyo primer número salió el 9 de julio de 1964 bajo dirección de José Constantino Barro. Luego quedó a cargo de Pedro Michelini hasta abril de 1966 cuando Raúl Jassén asumió la dirección y Jaime Lemos (un correntino que había sido militante de la ALN) asumió como secretario general $\underline{15}$. Tenía una tirada de 5 mil ejemplares, de distribución gratuita, $y$ era sostenido económicamente por Jorge Antonio, quien a su vez solía escribir en el periódico. El carácter marcadamente opositor al gobierno de Illia llevó a que Michelini, Jassén y Lemos fueran brevemente detenidos en junio de 1965 por el delito de desacato al haber publicado un artículo de Jorge Antonio. En marzo de 1966 Retorno pasó de ser un semanario a aparecer dos veces por semana. El último número salió el 15 de julio de 1966 cuando, junto a la revista de humor Tía Vicenta, fueron clausurados por el nuevo gobierno militar de Juan Carlos Onganía. Retorno tuvo una segunda época a partir de julio de 1970, esta vez dirigido por el ex militante del MNA Edmundo Calabró. Esa etapa contó con reportajes a Rucci y a los “compañeros universitarios peronistas de la CGU”, el secretario general de la junta metropolitana José María Castiñeiras y los secretarios ejecutivos José Luis Cordero y Ricardo Bernabé Molina.

Senkman (2001: 296) ubica al periódico Retorno como hispanista y católico, admirador de las ideas de José Primo de Rivera. Un artículo de la revista Leoplan de mayo de 1965 señalaba que Retorno 
(entonces dirigido por Jassén) tenía abiertas simpatías por las concepciones fascistas y era financiado por Jorge Antonio. Los vínculos de Retorno con Jorge Antonio pueden verse en los frecuentes editoriales que solía publicar en el semanario, así como también en la presentación de su libro ¿Y, ahora qué?, publicitado ampliamente en el número 79 de enero de 1966.

\section{Del antisemitismo al antisionismo}

Durante la década de 1960 es posible registrar un cambio importante en el discurso antisemita tanto del peronismo de derecha como del nacionalismo. Una de las razones de esta transformación se debía a la llegada a la Argentina en 1962, del tunecino Hussein Triki como representante de la Liga Árabe $\underline{16}$. Esta organización se involucró en el lanzamiento de campañas callejeras en las cuales se señalaba al sionismo como el mal mayor de la Argentina y en el armado de diversas redes y contactos con figuras del peronismo y del nacionalismo. El 22 de abril de 1964 en el Centro Honor y Patria hubo un homenaje a Hussein Triki. Entre los presentes se encontraban el ex gobernador de Buenos Aires Manuel Fresco, el presidente del bloque de diputados justicialistas Juan Luco (quien señaló que pediría una investigación sobre los campamentos de las juventudes argentinas sionistas), el legislador del partido provincial tucumano Bandera Blanca Isaías Juan Nougués, los abogados peronistas Alberto Baldrich, Pedro Michelini, el historiador José María Rosa, el comodoro Arca, el miembro del heptunvirato coordinador justicialista Carlos Gallo, los secretarios del bloque de diputados pertenecientes al justicialismo y a los Movimientos Populares Provinciales: Muñoz Aspiri y Pérez Pardo, entre otros. $\frac{17}{17}$

Cinco días después, se realizó otro acto del acto en el Teatro Buenos Aires, con el propósito de conmemorar el aniversario de la Liga Árabe. Allí habló el secretario del Movimiento Juvenil Argentino-Árabe Omar Hassum, quien pidió luchar por la liberación del pueblo argentino y contra el sionismo internacional. Entre las varias adhesiones se contó con la del secretario general de la CGT José Alonso, quien días después negó compartir los conceptos antisemitas vertidos por los oradores. Según Kilstein (2010) en el acto se encontraban militantes de Tacuara y GNR que coreaban consignas como "Mueran los judíos” o “Judíos a la Horca”.

El 31 de julio de 1964, la Liga Árabe empapeló la ciudad de Buenos Aires con un afiche que señalaba al sionismo como causante de la explosión de la calle Posadas $\frac{18}{}$, el contrabando de drogas y otros delitos. Se intentaba vincular el caso Alterman con la existencia de una "conjuración sionista totalitaria para apoderarse del poder” en la Argentina. Respecto a la campaña iniciada por Triki, sostiene Kilstein que el tunecino forzaba los argumentos hasta hacerlos coincidir con las acusaciones tradicionales que conforman la mitología clásica antijudía. Según estos mitos, los judíos mantenían una doble lealtad; rechazaban integrarse a las naciones que los recibían; eran conspiradores naturales y urdían planes para apoderarse de los resortes del mundo entero. Para este último propósito, controlaban los medios, la opinión pública y las finanzas mundiales; al mismo tiempo agitaban y lideraban Movimientos subversivos y revolucionarios con el fin de quebrar y dominar las sociedades (Kilstein, 2010).

Para el cumplimiento de su propósito, Triki logró establecer una alianza con Tacuara y la Guardia Restauradora Nacionalista, a las que subsidió a sus estructuras y actividades. También logró reunir a 
otras figuras de la derecha declaradamente antisemitas como el diputado Isaías Nougués, el sacerdote Julio Meinvielle, los militares brigadier (R) Gilberto Hidalgo Oliva (con asiento en la base militar de Morón), el brigadier (R) Cayo Antonio Alsina, el profesor Walter Beveraggi Allende y el diputado peronista Juan Carlos Cornejo Linares. $\underline{19}$

Basándose en una denuncia de Triki de que los campamentos de las juventudes sionistas eran “destinados al adiestramiento paramilitar de jóvenes argentinos de religión judía” el diputado justicialista Cornejo Linares presentó el proyecto (que no prosperó) de constituir una “Comisión Especial Interparlamentaria de Actividades Antiargentinas”. $\underline{20}$ En su proyecto advertía sobre "la existencia de la peligrosa conspiración sionista-comunista”. En los fundamentos de su presentación, Cornejo Linares se hacía eco de las denuncias del brigadier Gilberto Hidalgo Oliva, quien sostenía que "El sionismo actuando en consonancia con la masonería y el comunismo ateo, trataría de desterrar la enseñanza de la religión católica en la escuela argentina, lograr el reconocimiento legal del comunismo y obtener la disolución de la familia cristiana por medio de una legislación adecuada”. $\underline{21}$ A su vez, el diputado acusaba a Frondizi de ser el primer presidente sionista y sostenía que (su) énfasis en el carácter pluralista de la Argentina era una maniobra del sionismo. En un libro posterior, sostuvo el mismo argumento al decir que "Los objetivos del sionismo están en la procura del dominio del mundo mediante el establecimiento de un nuevo orden que permita la hegemonía internacional de la nación judía sobre todas las naciones en cumplimiento de su misión mesiánica.” (Cornejo Linares, 1966: 128). El proyecto de ley de Cornejo Linares fue editado como libro por la editorial Tacuarí en 1964 y aparentemente envió un ejemplar a Perón, quien lo leyó y le respondió por carta el 9 de octubre de 1964:

"Mi querido compañero: He recibido su libro, "El Nuevo Orden Sionista en la Argentina" que he de leer con sumo interés y le agradezco su recuerdo y su saludo que retribuyo con mi mayor afecto. El tema abordado es apasionante porque "mete la uña" en una de las más grandes internacionales de las que dominan este momento del mundo y contra las cuales parecen reaccionar decididamente todos los hombres realmente libres que no quieren hipotecar los pueblos a la férula de los grandes poderes ocultos de la ignominia”. $\underline{22}$

Raúl Jassén usó la carta de Perón para insistir en el apoyo del líder a las denuncias que realizó sobre el sionismo en la Argentina. Así lo dijo explícitamente en un artículo: “de ahora en adelante, respecto al sionismo será necesario hablar del PRONUNCIAMIENTO DE PERON, ya que sus palabras llevan, además del peso de su posición política de Caudillo el respaldo de su experiencia como Jefe de Estado”. $\underline{23}$ La denuncia del sionismo convergía con la crítica a la sociedad pluralista, que según Jassén, el sionismo impulsaba para lograr la disolución de la nacionalidad argentina. $\underline{24}$ Esta denuncia coincidía con la sostenida por Cornejo Linares en El nuevo orden sionista en la Argentina y tenía que ver con el rechazo de los nacionalistas a aceptar el criterio de sociedad pluralista al país. Como ha demostrado Rein (2015) esta concepción también se hallaba presente en figuras del nacionalismo forjista como Arturo Jauretche, quien en una polémica en diciembre de 1964 en la revista Horizonte con Jaime Finkelstein, sostenía que no podía haber en el país judíos que se reivindicaran sionistas porque eso era incompatible con la nacionalidad argentina. 
El 10 de agosto de 1964, Cornejo Linares fue homenajeado por su proyecto de ley para la creación del "Comité de Actividades Antiargentinas". La dirección del acto estuvo a cargo del Brigadier (R) Gilberto Hidalgo Oliva, un oficial de la Fuerza Aérea, con una marcada trayectoria antisemita. Entre los presentes estaban Triki; el sacerdote Amancio González Paz, los abogados Delgado, Foss, y Beveraggi Allende (profesor de la Facultad de Derecho), y Gerardo Valenzuela, comandante nacional de la GRN. El brigadier Cayo Alsina, ex comandante de la Fuerza Aérea Argentina, envió un telegrama de saludo a los comensales. Según informa la prensa, se gritaron consignas antisemitas durante la reunión, mientras Triki era elogiado por todos los oradores que equipararon el sionismo y el judaísmo con "actividades anti-argentinas". $\underline{25}$

El 17 de mayo de 1965, en una reunión de la Federación de Entidades Árabes, para conmemorar el $17^{\circ}$ aniversario de "la expulsión de los árabes de Palestina" y "del genocidio en el que cientos de árabes perdieron la vida." hablaron dos parlamentarios: Cornejo Linares y Nougués. Otro orador fue el sacerdote antisemita Elias Andraos, quien declaró: "Después de haber crucificado a Jesús, el pueblo de Israel no tiene misión alguna en Palestina. Ellos deben abandonar esa tierra". $\underline{26}$

Una muestra de esta cercanía con la Liga Árabe fue la invitación del 28 de mayo de 1965, a Cornejo Linares junto con el diputado Luis Augusto León y los Senadores Eduardo Gammond y Dante A. Lovaglio, por EsamHelmyEl Masry, director de la oficina de la Liga Árabe en Buenos Aires a visitar la República Árabe Unida, el Líbano, la República Árabe Siria y el Reino Hachemita de Jordania. $\underline{27}$. El viaje se realizó entre julio y setiembre, y el diputado mantuvo entrevistas con Amin El Hafez y GamalAbdelNasser. En marzo de 1966 visitó a Perón en Madrid. $\underline{28}$

En su intento de desacreditar al Estado de Israel, la Liga Árabe encontró en el tradicional antisemitismo de buena parte de la derecha argentina y en algunos sectores del peronismo un punto de apoyo y la oportunidad de dar a su prédica notoriedad pública y efectividad discursiva (Kilstein, 2010). Al mismo tiempo, este accionar dejó una impronta en el discurso de agrupaciones nacionalistas católicas y peronistas como Huella, Retorno y Patria Libre. Esta convergencia, a su vez, produjo la reformulación del antisemitismo en una variante antisionista y anti-izquierdista. En palabras de (Kilstein, 2010): “En el mito de la conspiración judía-sionista, los agentes de la confabulación aparecen vinculados no sólo al judaísmo y a la masonería sino también al comunismo, al socialismo y al trotskismo”.

Para mediados de la década de 1960 la denuncia del complot judío pasó a ser englobado en un nuevo concepto: sinarquía. Éste fue difundido originalmente en el peronismo de derecha a través del intelectual peronista Carlos Alberto Disandro $\underline{\underline{29}}$. En 1965, la difusión de las ideas de Disandro no sólo se hacía a través de la revista La Hostería Volante sino también de cursos y charlas en la Asociación de Trabajadores del Estado de La Plata y en locales de otros sindicatos. Desde la década de 1960 Disandro venía denunciando los cambios que se producían en la Iglesia Católica $\underline{30}$ con elConcilio Vaticano II, la Encíclica Populorum Progressio y el accionar del Monseñor Jerónimo Podestá, precursor del tercermundismo y presidente de la comisión encargada de la difusión de la Encíclica. Según relataba Disandro en una carta a Perón del 24 de julio de 1967:

"hay mucha gente del Movimiento entusiasmada con la figura del obispo de Avellaneda, a quien sostienen, promueven y dan alas, seguramente porque ignoran las calidades de 
tal monseñor. Pero yo ya lo denuncié en 1964, como aliado del judaísmo sionista, de la masonería y otras fuerzas sinárquicas, como Ud. podrá ver en mi trabajo Helenismo, Cristianismo, Judaísmo (respuesta a Mons. Podestá) y que le obligó a replegarse un tiempo.” Citada en Gurucharri, 2001: 163)

Según Ladeuix (2007) en virtud de los contactos que mantenía con sectores sindicales y peronistas en sus conferencias, Disandro se acercó en 1966 al mayor (R) Bernardo Alberte, para advertir sobre los peligros de la “infiltración comunista”. En 1968, Alberte fue nombrado delegado de Perón. En el marco de la Organización de Estudios y Acción Nacional (OEAN), fundada por Alberte con la intención de nuclear a los oficiales dados de baja por la Revolución Libertadora, Disandro dio varias conferencias sobre el peligro del “frente del Algodón” 11 reproducidas en el libro La estrategia de un poder sinárquico. Según su relato, (Disandro, 1973), tuvo el honor de hacer llegar al general Perón, entonces exiliado en Madrid, una copia de este ensayo político. Ello motivó una especial invitación del caudillo justicialista y una entrevista en la capital española en enero de 1967.

El impacto que causó la prédica de Disandro sobre la sinarquía puede verse en la carta que Perón le envió a Alberte el 25 de agosto de 1967:

"Él tiene una misión que hace tiempo le di para esclarecer en los ambientes universitarios y profesionales algunas cuestiones peligrosas que la gente suele pasar sobre ellas desaprensivamente, tal como puede suceder en este punto concreto a que me refiero en este momento: Comisión Populorum Progressio. (...) En cuanto a que el Dr. Disandro pueda hablar con nuestra gente y formar lo que él llama "repetidores" no creo que pueda ser sino provechoso porque lo que nuestros muchachos necesitan más que nada es esclarecimientos para no caer en las numerosas trampas tendidas. Sus conferencias, desde la de Toynbee hasta la de Brasil, pasando por la de la sinarquía, como sus publicaciones anteriores y posteriores han sido siempre muy buenas y peronistas. Por eso es que yo ya le encargué la tarea de realizar ese trabajo entre los universitarios y profesionales.” (Citado en Gurucharri, 2001: 160)

A partir de allí la prédica sobre la sinarquía se fue extendiendo al resto del Movimiento peronista y particularmente en el sector de derecha. $\frac{32}{}$ En la revista Frontera 67 dirigida por Jassén luego de la clausura de Retorno puede encontrarse la primera mención a la sinarquía que no pertenece a Disandro $\underline{33}$. Allí en la introducción a un texto de José Antonio Palacios (probablemente escrita por Jassén) figuraba la siguiente mención:

"La imposición de un gobierno mundial -tal como lo preconiza la sinarquía- no es, ya una lejana abstracción sino una dramática y concreta realidad. Entre nosotros, los argentinos, un puñado de hombres de pensamiento y de políticos de singular talla moral e intelectual -Meinvielle, Cornejo Linares, Baldrich, Di Sandro (sic), Juan Puigbó, entre otros - se han ocupado del tema en la conciencia de que la sinarquía es la potencia supranacional que asfixia nuestra personalidad nacional, continental y universal. (...) es decir, la creación del gobierno universal regido por los poderes del dinero. $\underline{34}$

En la visión de Disandro, la sinarquía era entendida como "la convergencia radical de principios de poder que obran en el mundo desde los orígenes de la humanidad”. La revolución nacional del 
gobierno peronista había sido abortada por la convergencia de los poderes sinárquicos, dentro de los cuales figuraban actualmente los sectores liberales, jesuitas, la masonería, el judeo-bolchevismo y el catolicismo posconciliar. A esto se sumaban los pseudo-imperios de Estados Unidos y la URSS que buscaban destruir la esencia espiritual del resto de las naciones del mundo. Como se puede apreciar, en la concepción de Disandro se encontraban ampliadas las viejas teorías conspirativas ya presentes en la derecha. La novedad y difusión del término se dio cuando Perón lo utilizó públicamente: en su libro La Hora de los pueblos:

El mundo actual, influenciado por las "grandes internacionales" creadas por los imperialismos, está enfrentando a una sinarquía internacional que ha venido manejándolo. Como ha sucedido siempre, cuando los pueblos comienzan a recobrar su libertad, grandes movimientos sociales despiertan con todo el poder e intensidad que las circunstancias les ofrecen. (Perón, 1968)

Con un total de cinco menciones en las 147 páginas de La Hora de los pueblos esta era la primera vez que Perón mencionaba de manera pública la palabra sinarquía (antes lo había hecho por carta a Disandro). A partir de su incorporación al "vocabulario oficial” del peronismo la palabra sinarquía se difundirá rápidamente y sobre todo entre la derecha peronista.

\section{El discurso antisemita en los años setenta}

Para la década de 1970 es posible observar la extensión del concepto de sinarquía a todas las publicaciones del llamado peronismo ortodoxo llegando a convertirse en un verdadero leitmotiv. Revistas del peronismo de derecha como Patria Peronista, El Caudillo, Patria Barba, Primicia Argentina y Consigna Nacional, incluían en todos sus números un informe sobre esta conspiración sinárquica. También lo hacían las organizaciones de la derecha como Juventud Peronista de la República Argentina (JPRA), CNU, Juventud Sindical Peronista (JSP), Comando de Organización (CdeO) y ALN en sus declaraciones públicas, volantes, solicitadas y consignas. $\underline{35}$ A partir de 1973, el uso de las palabras sinarquía, sinarcas y conspiración sinarquica se repite hasta el hartazgo en toda la derecha peronista. En El Caudillo se explicaba a sus lectores el significado de esta palabra:

“¿Qué es pues, la sinarquía? Podríamos decir, aventurando una definición, que es la unidad operativa de un conjunto de potencias clandestinas, que en todos los órdenes (político, económico, cultural y religioso) contribuyen a la formación de un gobierno mundial invisible. (...) Sinarquía, pues, en sentido etimológico menta la convergencia radical de principio de poder que gobierna al mundo. Es decir, los poderes visiblemente contrapuestos (syn) en el mundo se coaligan en al sinarquía. $\underline{36}$

De esta forma tanto el capitalismo como el comunismo, la masonería y el judaísmo se veían como fuerzas antagónicas con el mismo fin: la destrucción de la nación argentina, católica y peronista. Montoneros, José BerGelbard, las empresas transnacionales, los liberales y los comunistas eran partes del complot mundial de la sinarquía.

Precisamente cuando se produjo la promulgación de la ley de repatriación de los restos de Juan Manuel de Rosas, la Alianza Libertadora Nacionalista organizó un acto público donde se incitó 
abiertamente contra los judíos:

"El 22 de octubre [de 1974], los socios de la Acción Nacional Argentina se dieron cita en el teatro municipal “Armando Discépolo" con la presencia del presidente provisional del Senado Dr. José Antonio Allende, el decano de la facultad de Filosofía y Letras de UBA, presbítero Raúl Sánchez Abalenda; el interventor federal de la provincia de Formosa, senador nacional Juan Carlos Beni; el jefe de la Alianza Libertadora Nacionalista, Juan Queraltó, y notorias figuras del peronismo ortodoxo y del nacionalismo tradicional no peronista. Hicieron uso de la palabra Ricardo Arias Duval por la ALN, el asesor gremial de la Universidad de Buenos Aires, Eleuterio Cardozo, quien habló en nombre del rector Alberto Ottalagano; el presidente del Instituto de Investigaciones Históricas Juan Manuel de Rosas, Alberto Contreras, y el senador nacional Juan Carlos Cornejo Linares. Entre cánticos y vítores a Rosas, se escuchaba la amenaza a viva voz: Mazorca, Mazorca, judíos a la horca!!!” (Senkman, 1986: 143)

Justamente mediante esta consigna la derecha peronista buscaba asociar positivamente la figura de Rosas (denostada por el liberalismo argentino) con la de Perón, quien en 1830 alentó la formación de una organización parapolicial conocida como la Mazorca. Como bien recuerda (Tcach, 2001, pág. 12) la presencia de judíos en el peronismo progresista como José B. Gelbard (ministro de Economía de Cámpora), o de izquierda (como Marcos Osatinsky, dirigente histórico de las FAR), demostraba que los judíos peronistas estaban del otro lado de la barricada.

Como una variante del mismo estribillo también se cantaba "Perón mazorca, los bolches a la horca" y como hizo la JPRA en el acto del 20 de noviembre de 1973: "Con las tripas de Santucho, vamos a hacer una horquita, para colgar a los trotskos, disfrazados de peronistas”. Por último, la consigna: “En la patria de Perón, ni judío ni masón” y que fuera vitoreada con motivo del nombramiento del fascista Alberto Ottalagano, como rector normalizador de la Universidad de Buenos Aires en 1974 (Tcach, 2001: 50) sintetiza en gran medida la cultura política del peronismo de derecha.

En unos de sus últimos números, El Caudillo se hacía eco de las teorías del complot y sostenía que se estaba asistiendo a "la última etapa de un proceso conspirativo". Entre los integrantes de esta conspiración figuran "los partidócratas liberales, los ‘progresistas’ de la izquierda parlamentaria, los guerrilleros de la guerra revolucionaria, la derecha financiera y usurera y los sectores que alguna vez formaron parte del peronismo". Todos coincidían en "el ataque despiadado a la figura e investidura de Isabel Martínez de Perón”. Aparecían luego las fotos de Gelbard y Timerman precedidas del siguiente epígrafe: "La trilogía de la conjura sinárquica que asola a nuestro país: Gelbard es quien paga a los alcahuetes de turno; Timerman es quien difunde el macaneo de su diario para 'exquisitos' y el enano Perette en la cámara propicia cuanto fenómeno sea posible descubrir para hacer despelote”. El artículo terminó señalando que cuando llegue la hora de la verdad “Timerman se irá a hacer sionismo a Israel”. $\underline{37}$

Asimismo, como he analizado en otro trabajo (Besoky, 2016a), el antisemitismo también se reflejaba en el humor gráfico de la derecha peronista. Sin embargo, no era exclusivo, ya que el uso de caricaturas antisemitas había formado parte de varias publicaciones de la derecha nacionalista en décadas anteriores. Por ejemplo, Alianza en las décadas del ' 40 y ‘50, y en Tacuara, revista de la UNES, donde una de las tiras ocasionales titulada "Samoil Cipayosky” $\underline{38}$ se encargaba de satirizar a 
los judíos en su vida cotidiana (Galván, 2008). Una de las novedades que traía El Caudillo, era que la representación del militante de Montoneros se caricaturizaba recurriendo a la tradicional iconografía antisemita (Senkman, 1986). De esa manera y producto del conflicto con la izquierda del movimiento, los redactores del semanario buscaban deliberadamente asociar al ya clásico repertorio de los enemigos: el judaísmo y comunismo a los sectores de izquierda del peronismo.

Pero el antisemitismo no estuvo presente sólo en la caracterización de la Tendencia, sino también en otras figuras de la esfera pública como el ministro de Economía Gelbard o el director de La Opinión, Timerman. Las críticas a Gelbard se hicieron más frecuentes a partir de la muerte de Perón, $\underline{39}$ mientras que para Timerman se encontraron con motivo de un conflicto laboral en el diario, una caricatura de su director en el escritorio tenía un cartelito: "Federación sinárquica mundial, primer presidente”. Frente a él, empleados famélicos levantaban carteles: "Gringo cerdo. ¡Los criollos necesitan comer!”. Impasible, Timerman enciende un habano con un billete y responde con marcado acento ídish: “-¿istánmishiguenes? No poido, che... ¡No mi alcanza platita, linda para concretar negocios de coima! ¿No ves, paesano, qui tengo qui hacer un blanqueo y rajarme al exterior?". $\underline{40}$

Finalmente para la década de 1980 todavía subsistía el discurso antisemita en algunos personajes del peronismo de derecha. Este fue el caso de Alberto Ottalagano quien en declaraciones en el programa Tiempo Nuevo, conducido por Mariano Grondona y Bernardo Neustadt y emitido por canal 13 el 6 de septiembre de 1983, se definió como fascista mientras advertía que el peronismo era un fascismo cristianizado. Allí planteó que "no se puede ser peronista sin ser nacionalista y sin ser católico”. Lo que motivó el siguiente diálogo con los periodistas:

"P: ¿No puede haber un peronista que no sea católico?

R: Un peronista que no sea católico es muy difícil.

P: El embajador argentino en Israel era judío.

R: Bueno era judío, muy bien, puede haber, pero en realidad la doctrina medular del peronismo es la concreción histórica del catolicismo; es la temporización del catolicismo. (...) un peronista no puede darse el lujo de no ser católico y no ser nacionalista, de lo contrario es una aberración (...) Mi condición de católico me impide ser antisemita, pero debo prevenir lo siguiente, que los judíos no tienen ninguna titularidad para tener injerencia e intervenir en la Argentina (...) No son nadie los judíos para interferir en la política argentina y para impedirme a mí, que soy un viejo militante al servicio de la nación. (...) Les aconsejo a los judíos que se tranquilicen, que se hagan notar lo menos posible para no irritar la ira aria."ㅆ1

Las declaraciones de Ottalagano de los judíos peronistas como una aberración, su ninguneo y la recomendación de no irritar la "ira aria” conmovieron fuertemente el espectro político y le valieron fuertes cuestionamientos desde los editoriales de los principales periódicos, la DAIA y del mismo movimiento peronista. Entre las críticas figuró la de un peronista judío que había sido funcionario del gobierno: Alberto Manguel. 
“En mi carácter de argentino peronista descendiente de judíos y con 40 años de militancia peronista le niego toda autoridad a este seudo educadora que haga gala de un fascismo tal y niegue el asesinato de 6 millones de judíos víctimas de esos psicópatas. (...) Recuérdole también a este señor que en 1955 por mediación del general Perón este argentino judío, siendo embajador argentino en Israel viajó a Buenos Aires y asiló en su casa de la calle Palpa 2368 de Capital sus entrañables amigos obispo monseñor De Andrea y Franceschi. (...) Sí le exijo que nunca más se permita comparar al general Perón con Hitler y que no olvide toda la ayuda que el presidente Juan Perón y Eva Perón prestaron al naciente Estado de Israel, a saber la radicación de 30000 judíos sin documentación..."쓰

Las opiniones vertidas por Ottalagano y Manguel, y su pertinencia al mismo movimiento, son un buen ejemplo de la convivencia de peronistas judíos y antijudíos en el peronismo.

\section{Conclusiones}

Como hemos visto, en el campo nacionalista el antisemitismo adquirió una importancia central y se combinó con una mirada conspirativa que fomentó prácticas de discriminación y violencia. No solo hubo actos de violencia antisemita durante el 17 de octubre de 1945 (y posteriormente) sino que varias figuras del peronismo como el general Luis Perlinger, el general Juan F. Velazco, el Dr Santiago Peralta y el sacerdote Virgilio Filippo, compartían este discurso antisemita. Sin embargo, hemos visto también que difícilmente pueda caracterizarse de antisemita al gobierno peronista en tanto y en cuanto muchos de estos funcionarios fueron obligados a renunciar en $1947 \mathrm{y}$ en el caso de Filippo debieron atenuar su antisemitismo una vez elegido diputado nacional. Al mismo tiempo, desde el gobierno peronista se fomentaba la tolerancia religiosa y se incluía a varias personas de la colectividad judía en cargos del gobierno. El antisemitismo permaneció de todas formas dentro del discurso de la ALN y tolerado por el gobierno hasta 1953 cuando ésta fue intervenida por Guillermo Patricio Kelly. Durante la resistencia peronista el discurso antisemita y el accionar violento contra la comunidad judía volvió a emerger en sectores escindidos de la ALN como Tacuara y en otras organizaciones del nacionalismo que se vincularon al peronismo como el MNA. Asimismo, publicaciones periódicas durante la resistencia como Huella, Retorno, Patria Bárbara y otras, que reunían a militantesperonistas como Jassén, Michelini, Baldrich y Cornejo Linares, suscribieron a la idea del complot judío mundial. Con la llegada de Triki en los años sesenta, la cuestión de medio oriente y las denuncias del Estado de Israel, sumado a las repercusiones por el secuestro de Eichman, transformaron las clásicas denuncias del judaísmo en un antisionismo.

Otra de las novedades de esos años fue que la identificación de los enemigos se estructuró en base al concepto de sinarquía que permitía englobar una amplia gama de actores que incluían al judaísmo, el sionismo, el marxismo, el liberalismo, los jesuitas y los sectores progresistas. Precisamente el término sinarquía se volvió permanente dentro de la derecha peronista e incluso en el peronismo ortodoxo, aunque nunca fue central en el pensamiento de Perón ni tenía el alcance que la derecha pretendía darle. En el marco del tercer gobierno peronista, el uso del término infiltrados o la negación de la identidad peronista a los sectores de izquierda fue bastante recurrente y parte esencial del discurso anticomunista de la derecha. Dentro de este discurso, el antisemitismo se reflejó tanto en su prensa periódica como en los actos políticos y acciones llevadas a cabo. Retomando entonces lo señalado por Rein al inicio de este artículo, podemos convenir que si bien 
es cierto que difícilmente pueda señalarse al peronismo o a Perón como antisemita, si encontramos un marcado antisemitismo en el sector derechista del movimiento que perduró desde los inicios hasta la década de 1980.

\section{Notas}

1 Precisamente (Buchrucker, 1987) destaca que la idea de la conspiración, tributaria del pensamiento contrarevolucionario europeo, estaba presente en el nacionalismo argentino desde el golpe Uriburu.

2 Sobre la ALN véase Besoky, 2014; Capizzano, 2013; Furman, 2014.

$\underline{3}$ “Las aspiraciones de Israel”. Alianza, №12, 2º quincena de febrero de 1945, p 12.

4 “El capitalismo judío en el Buenos Aires de 1889”. Alianza, No 13, $1^{\circ}$ quincena de marzo de 1945, p. 11

$\underline{5}$ "Los obreros no deben hacerle el juego al derrotado fascismo: el coronel Perón no es racista”, $L a$ Época, 20 de octubre de 1945, p. 2. Citado por Lvovich, 2001: 64

6 Para un registro detallado del accionar de Peralta véase (Goñi, 2009, págs. 74-78 y 145-146)

$\underline{7}$ “Mensaje político a los israelitas de la Argentina”, publicada en La Nación del viernes 5 de marzo de 1948.

$\underline{8}$ Alianza, No 103, 15 de agosto de 1951, Buenos Aires. (BN)

$\underline{9}$ Alianza, año II, $\mathrm{N}^{\circ}$ 26, primera quincena de octubre de 1954, p.1. (Archivo personal)

10 El MNT se había conformado originariamente en los años finales del peronismo como parte del sector juvenil de la ALN. Este sector solía editar como una publicación titulada Tacuara de donde tomaron el nombre para la organización.

11 “Reportaje al MNA” (CPM-Fondo DIPBA, Mesa “A”, Factor político, carpeta 37, legajo 145, folio 8).

12 Michelini, Pedro (1924-2004) egresó de la Facultad de Derecho de la UNLP en 1951, desempeñándose como abogado laboralista y asesor letrado de la Secretaría de Prensa de la Presidencia de la Nación hasta 1955; de la CGT de La Plata desde 1957 a 1967; de la Asociación de Empleados de Comercio; de la Mesa Obrera Textil de Berisso; de la Unión Personal Civil de la Nación y ATE de Ensenada, entre otros cargos. Fue apoderado de Juan Domingo Perón desde 1965 por institución del Dr. Vicente Leónidas Saadi, quien anteriormente había instituido en esa función al Dr. John Williams Cooke. Su actuación como apoderado de Perón tenía como motivo representarlo judicialmente en las causas penales y civiles que la autodenominada "Revolución Libertadora” le había instruido. Fue asesor técnico de Escuela Superior de Conducción Política del peronismo. Falleció el 14 de diciembre de 2004 en la ciudad de La Plata.

$\underline{13}$ Hijo del general Alonso Baldrich, nació el 20 de enero de 1898 en Buenos Aires y fue uno de los 
miembros iniciales del prestigioso Instituto de Sociología de la Facultad de Filosofía y Letras de la Universidad de Buenos Aires, creado y dirigido en 1940 por Ricardo Levene. De profesión abogado se desempeñó en el poder judicial, siendo además docente, conferencista y publicista en los institutos militares y en el círculo Militar, vinculado a Jordán Bruno Genta y Octavio Pico. En 1943 fue designado por el presidente Pedro Pablo Ramírez como interventor en la Provincia de Tucumán, para lo cual renunció al cargo de Ministro de Gobierno de la Intervención federal en La Rioja. El desempeño del Baldrich como interventor federal de Tucumán fue el primer experimento nacionalista bajo los postulados de la Revolución de junio de 1943: se quitó la personería a los partidos políticos, se impuso la enseñanza religiosa obligatoria en las escuelas públicas, a la par que se reconocía el sindicalismo de orientación católica dentro de la cooperación entre las clases empresaria y obrera. También acontecieron sucesos importantes con relación al patrimonio histórico provincial, ampliando los fondos documentales del Archivo Histórico, protegiendo los vestigios de la primitiva ciudad de San Miguel de Tucumán y las ruinas del Convento de San José de Lules, fundando el Museo Folklórico y reconstruyendo la Casa Histórica donde se juró la Independencia en 1816. En 1944 fue designado Ministro de Justicia e Instrucción Pública por el presidente Farrell, en reemplazo del nacionalista católico Gustavo Martínez Zuviría (luego de un breve interinato de J. Honorio Silgueira). Su gestión continuó la línea nacionalista elitista de Martínez Zuviría, pero más orientada al hispanismo y al nacionalismo económico. Se adhirió al peronismo y tuvo una activa participación durante la "Resistencia Peronista" escribiendo en varias publicaciones y fue asesor y docente de la Escuela Superior de Conducción Política del peronismo. En 1973 fue designado como Ministro de Educación de la Provincia de Buenos Aires por instancias de Peón durante la gestión del gobernador Oscar Raúl Bidegain y continuó luego que asumiera el vicegobernador Calabró. Falleció el 19 de diciembre de 1982 en Buenos Aires. Entre sus obras se destacan: Libertad y determinismo en el advenimiento de la sociedad política argentina (1949), Imperialismo y liberación Nacional (1967) y Manuelita Rosas, la reina del Plata: guión para cinematografía (1980). (Kraft, 1955)

14 Nació el 1 de enero de 1931 en Buenos Aires. Hijo de inmigrantes: padre sirio y madre española. Su padre había sido albañil y Raúl fue peón en establecimientos frigoríficos, molinos yerbateros y en construcciones antes de dedicarse profesionalmente al periodismo. En 1946, con tan solo quince años escribió su primer artículo en la revista Tacuara, órgano de la Unión Nacionalista de Estudiantes Secundarios (UNES). En 1954 colaboró en De Frente, órgano dirigido por John William Cooke. Pasó luego a dirigir Tribuna Sindical hasta su clausura en 1956, en donde pasó a colaborar con Luis Sobrino Aranda en la dirección del periódico Soberanía. Luego escribió en la revista Mayoría de los hermanos Jacovella. En 1959 este medio lo envía como corresponsal a España donde sus largos años de residencia en Madrid le permitirán entrevistar a Perón y conocer a personalidades como Nasser, estableciendo además una relación cercana con el empresario peronista Jorge Antonio. Producto de esta relación Jassén publicó Jorge Antonio. Un argentino frente a la oligarquía, (1961). El 10 de mayo de 1963 el diario español ABC de Sevilla registra la entrevista exclusiva de Jassén (como miembro de la agencia FIEL) a Ahmed Ben Bella en Argelia. Debido a su rol de periodista, presenció a lo largo de su carrera diversos escenarios bélicos y estuvo además en los sucesos de la Revolución Cultural China. En 1971, Jorge Antonio compró Primera Plana y colocó a Jassén, un hombre de su absoluta confianza según él mismo dijera, como parte del 
nuevo emprendimiento periodístico, desde donde firmó las notas bajo el seudónimo de Carlos Frank. Jassén también dirigió en los setenta el semanario Patria Bárbara y en 1974 la quincenal Consigna Nacional, claramente alineadas con la derecha peronista aunque críticos de López Rega. En 1979 se trasladó a Brasil donde dirigió la revista Acción Americano árabe, publicación de la embajada de Irak y donde conoció a Ione, una joven brasileña con quien vivió hasta sus últimos días y con quien tuvo a su hija, Yasmin. En ese período escribió varios poemas, aún inéditos. En 1983 figura como director junto a Mario Granero del semanario ElImpertinente. Entre 1988 y principios de los '90 aparece como colaborador de la revista Doctrina para el Movimiento nacional perteneciente a la Escuela Superior de Conducción Política y Sindical, dirigida por Norberto Chindemi. Estuvo junto a Carlos Menem entre finales de los ochenta y principios de los noventa pero luego se alejó disconforme con la orientación del menemismo. Murió el 11 de junio de 1992. Entre sus libros publicados figuran: Nasser, soldado de la Revolución Nacional (1961), Historia póstuma de Eva Perón, Biografia de Collar (1969), Argentina De Bolivar a La Trilateral (1970), Romper al peronismo!: la doctrina Justicialista, espírituhistórico de Perón (1976), Por la gloria de Inglaterra (1986), Seineldín: el ejército traicionado (1989), Sangre Petróleo y Sionismo (1990). (Hernández, 2007), (Jassén, 1976)

15 Señala (Carman, 2015, pág. 589) que muchos redactores provenían del periódico Huella. Aunque se diferenciaban de Retorno por el menor peso las discusiones político-filosóficas, estando más preocupado por la política coyuntural con el objetivo de agrupar los peronistas detrás del retorno de Perón.

16 Triki había nacido en Túnez en 1916 y desde muy adolescente se convirtió en militante de la resistencia contra los franceses. En su juventud, durante la Segunda Guerra Mundial, perteneció a "Neo-Destour" una organización en Túnez, que operaba con el consentimiento de las autoridades alemanas durante la ocupación nazi. Allí realizaba propaganda contra los aliados en colaboración con el Gran Mufti de Jerusalén, que estaba a cargo de las transmisiones nazis al Oriente Medio, y con emigrados árabes pro-nazis en Alemania. Fue detenido, condenado a muerte y luego absuelto. Especializado en historia y sociología, cursó la carrera diplomática. En junio de 1955 Hussein Triki estuvo en la Argentina en representación de la Asociación de estudiantes libres de Magreb, para participar de la Conferencia Internacional de Dirigentes Universitarios convocada por la Organización Mundial Universitaria (OMU). Según señalaba un informe redactado en aquella ocasión por el Jefe Nacional del Sindicato Español Universitario (SEU), Jorge Jordana Fuentes, miembro de la delegación española: “Triki reside en el Cairo, y está condenado a muerte por las autoridades francesas del país, huyendo de dicha condena se refugió en España en donde estuvo cerca de dos años. Es un gran amigo de nuestro país, habla correctamente el español y tanto en conversaciones privadas, como en intervenciones públicas no se recata de alabar la política que España sigue en África”. (Cerrano \& Peñalba, 2014, pág. 207). Al producirse la independencia de Túnez en 1956, Hussein Triki, con 40 años de edad, comenzó una nueva etapa de investigador y viajero. En 1957 publicó el trabajo He aquí Argelia para la Delegación del Frente Argelino de Liberación Nacional en América Latina. Representando a la Liga de los Estados Árabes, Triki fue designado director de la Oficina de esa organización en Buenos Aires entre 1962 y 1964. Como el mismo señalara había llegado al país para realizar una campaña publicitaria para "comunicar, difundir y esclarecer la ilegitimidad, violencia y carácter colonial e imperialista del Movimiento 
sionista” y "las consecuencias nefastas que sus acciones estaban teniendo sobre la población nativa árabe de la Palestina histórica”. Para esto contó con la revista Nación Árabe, dirigida por el mismo Triki y cuyo secretario general y jefe de redacción era un antiguo militante aliancista: Raúl Jassén. En setiembre de 1964 Triki abandonó la Argentina, probablemente para continuar su campaña en el exterior, pero cuando en julio de 1965 intentó retornar al país fue expulsado con la excusa de no poseer la documentación exigible En julio de 1965, luego de varias quejas por parte de la colectividad judía, Triki fue expulsado por intentar ingresar al país sin la documentación requerida. Se casó con Nadira Abdelhadi, pintora, escritora y poetisa argentina nacida en Coronel Brandsen, provincia de Buenos Aires. Para 1977 hay reportes que indican la presencia de Triki en Venezuela y la continuación de su campaña antisemita. Posteriormente residió en Brasil entre 1978 y 1998 y retornó a la Argentina en ese año. Defensor de la causa Palestina, en 1977 publicó el libro He aquí Palestina: El sionismo al desnudo (reimpreso en 2010). Durante las décadas del sesenta y setenta, fue delegado personal Juan Domingo Perón ante el mundo árabe-musulmán a través de una carta especial firmada por aquél. El 12 de mayo de 2012, luego de sufrir un accidente de tránsito, falleció en el hospital Fernández de Buenos Aires, a los 96 años de edad. (Kilstein, 2010).

\section{Véase Revista Nación Árabe, Año II Nº 13 y 14, mayo-junio 1964.}

$\underline{18}$ El 21 de julio de 1964, explotó un departamento en la calle Posadas 1168, causando la muerte a más de diez personas. Lo que en un momento se pensó que era un accidente motivado por un escape de gas, resultó ser un accidente en el manejo de explosivos de una naciente organización guerrillera: las Fuerzas Armadas de la Revolución Nacional (FARN) cuyo principal dirigente Ángel "Vasco" Bengochea murió en el estallido junto con sus compañeros y una familia que ocupaba un departamento contiguo.

19 Este diputado, considerado uno de los referentes del peronismo de derecha, nació en Salta el 9 de octubre de 1916, siendo sus padres Lucía Linares Uriburu y Julio Cornejo Uriburu, el primer gobernador yrigoyenista de la Provincia de Salta (1927-30) y hermano del primer gobernador peronista de la misma provincia Lucio Cornejo (1946-49). Las primeras letras las conoció en la Escuela Zorrilla y el secundario en el Colegio Nacional. La carrera de Derecho la hizo en tan solo dos años y tres meses en la Universidad Nacional de La Plata, donde fue militante de la juventud nacionalista universitaria platense en 1936 y de FORJA entre 1939 y 1945. Discípulo de Raúl Scalabrini Ortiz y fundador de la Unión Cívica Radical yrigoyenista de Salta en 1945. Dirigió el diario Norte entre 1945 y 1950 siendo también Diputado Provincial por el Partido Peronista (194652-55) y Diputado Nacional en 1955. Con el Golpe de Estado de 1955 estuvo detenido e incomunicado por 30 días. Ese año se convirtió en fundador e integrante del Consejo Superior en la Clandestinidad (22/10/1955) y organizador de la primera resistencia peronista e integró la primera asociación de abogados pro defensa de los presos políticos peronistas. Fue preso en enero de 1957 acusado de participar en la rebelión de Valle del año anterior. Meses después se exilió en España e integró el Comando Peronista de Madrid. Ese mismo año viajó a Caracas, actuando como colaborador de la Secretaría del General Perón en esa ciudad, miembro del Comando Táctico Nacional y Presidente de la Junta Reorganizadora del Partido Peronista en Salta (1958). De allí pasó a Panamá, Chile y Bolivia para volver finalmente al país en marzo de 1958, momento en que fundó el periódico Lealtad desde donde denunció el accionar antiperonista y al gobierno de Arturo 
Frondizi. Entre 1963 y 1966 fue Diputado Nacional por el Justicialismo.

20 Sobre su proyecto de ley véase: AR-HCDN-SP-DAPyM-Exp-827-d-1964.pdf. El mismo fue reproducido en Nación Árabe, año II, N¹5, agosto 1964 y editado en formato libro como (Cornejo Linares, 1964).

21 “Cornejo Linares.- Creación de una comisión interparlamentaria de actividades antiargentinas” AR-HCDN-SP-DAPyM-Exp-827-d-1964.pdf (p.9)

22 Carta reproducida en Patria Bárbara, Año I, No 4, 2da quincena de noviembre de 1964, p. 3 (IBAZ).

23 Patria Bárbara, Año I, No 3, 1ra quincena de noviembre de 1964, p. 5 (archivo personal).

$\underline{24}$ Así lo decía Jassén en el segundo número de Patria Bárbara: "La tesis sionista es la de que nuestro país no constituye una nacionalidad, de que nuestra composición social es "aluvional" y no existen entre los argentinos nexos comunes de cultura, idioma, moral, religión, tradiciones y unidad telúrica. (...) Y quiere todo esto porque la "pluralidad" cubre, bajo su asqueante manto, la mano y las garras de la bestia sionista. Cubre la necesidad de dominación total que el Movimiento sionista internacional quiere ejercer sobre la Nación Argentina...”.

$\underline{25}$ Véase el reporte de la Jewish Telegraphic Agency, disponible en: http://www.jta.org/1964/08/11/archive/argentine-anti-semites-honor-deputy-deliver-anti-jewishspeeches\#ixzz2zI4vNaMF.

26 Véase reporte de la Jewish Telegraphic Agency, disponible en: http://www.jta.org/1965/05/19/archive/anti-semitic-demonstrations-held-in-buenos-aires-bybanned-groups\#ixzz2zIBho8S7

27 Véase la comunicación de Cornejo Linares al Congreso de la Nación respecto a la invitación efectuada por la Liga Árabe en: AR-HCDN-SP-DAPyM-Exp-105-ov-1965.pdf

$\underline{28}$ Posteriormente Cornejo Linares dirigió en Salta el Centro Federal, organización adherida al Centro Federal Nacional, presidido por Manuel de Anchorena, cuyo objetivo era la divulgación de la personalidad de Rosas. En 1972 coordinó la Lista Única del Movimiento en Salta y en 1973 asumió como Senador Nacional por esa provincia. Como parlamentario tuvo un activo accionar destacándose entre otros la Ley de Aguas, considerada como lo mejor que se había redactado sobre este rubro a nivel nacional. Entre sus obras se encuentran: Historia de un despojo (1950), Petróleo y Miseria (1963), El nuevo orden sionista en la Argentina (1964), El nuevo orden sionista en la Argentina (1964), Política-Nacionalismo-Estado (1966), Argentina, provincia sinárquica y Política, nacionalismo y Estado, Acerca de Rosas (1975). No se puede olvidar al libro sobre el famoso caso "Aluar", investigado siendo senador nacional que originó la creación de una comisión bicameral para el estudio del contrato celebrado entre el Estado y ALUAR S.A.I.C. Falleció el 16 de mayo de 1980.

29 Disandro había nacido en 1919 en La Plata, pero se trasladó a Córdoba en su adolescencia, lugar donde estudió en el exclusivo Colegio Monserrat, de la Universidad de Córdoba. Allí tomó contacto con quien sería su maestro espiritual, el filósofo Nimio de Anquín quien, al igual que el filósofo 
Carlos Astrada regresaba de asistir en Alemania a las clases de Martin Heidegger y Ernst Cassirer. Por entonces, Nimio de Anequín pasaba a ser conocido como fundador de la Unión Nacional Fascista Católica de Córdoba (1936) y fuertemente influenciado por las ideas de José Antonio Primo de Rivera. Al recibirse de bachiller, Disandro regresó a su ciudad natal donde poco después se recibió de profesor y más tarde como Doctor en Letras, en la Facultad de Humanidades, con una traducción y tesis introductoria sobre la poética de Lucrecio (De Rerum Naturam), ahora apadrinada por el profesor de latín y poeta Arturo Marasso. Conoció al coronel Perón, con motivo de los sucesos universitarios en la revolución de 1943, pues Disandro se distinguió desde sus años juveniles por el combate contra la Federación Universitaria Argentina (FUA), apoyó en consecuencia la gestión inicial del General a quién conoció y trató personalmente desde 1944, en ocasión del discurso pronunciado en el Colegio de la Universidad de La Plata. Trabajó luego en la Secretaría de Trabajo y Previsión, y colaboró desde entonces en la cuestión universitaria, Ley 13.031. Fue consejero de la Facultad cuando se aplicó esa ley en los claustros universitarios y fue Profesor titular de Lenguas Clásicas desde 1944, concurso realizado definitivamente en 1946, bajo la primera presidencia del General Juan Domingo Perón. De manos del presidente recibió a comienzos de 1947 el diploma de profesor titular de la Universidad de La Plata, en el Salón Blanco de la presidencia.

Tras el golpe de Estado de 1955 Disandro fue removido de su cátedra de la UNLP junto con 4.000 profesores en todo el país, incluyendo a su maestro Nimio de Anquín en Córdoba. Durante la proscripción peronista, comenzó una etapa de vasta producción intelectual, panfletaria, literaria ensayística y poética. En la obra panfletaria se destaca la creación y dirección de la revista $L a$ Hostería Volante (1959) título tomado de la novela homónima de G. K. Chesterton, y en la que congrega a algunos seguidores que comienzan a trabajar el concepto de conjura o sinarquía en función de Los Protocolos de los Sabios de Sión. En paralelo a su producción panfletaria, editó sus propios libros en Hostería Volante, y con abordaje de la obra poética de Leopoldo Lugones. Luego se embarcó con R.M.Rilke, San Juan de la Cruz, Luis de Góngora, Lope de Vega, Dostoievsky, etc. Finalmente, en julio de 1972, Disandro publicó -en su editorial- su único libro de poemas, el que tituló: Sonetos - a la gloria del fuego. Desde los años sesenta ejerció su influencia sobre jóvenes tacuaristas desde el Instituto Cardenal Cisneros, donde nacería la Concentración Nacional Universitaria. (Ladeuix, 2007), (Axat, 2011).

30 En uno de sus artículos de La Hostería Volante de 1960, titulado "El frente del Algodón” Disandro advertía: “después del avance incontrolado del marxismo, después del control de muchos gobiernos por una trenza judeo-marxista, háblase ahora, en circunstancias harto sospechosas, de un frente social-cristiano, que ha comenzado a actuar en solidaria acción con el poder marxista que nos dirige. (...) Este frente del algodón a triunfado hasta ahora en el campo de la enseñanza, de la economía, de los planteos institucionales. Resta que triunfe en una tarea política más concreta...”. En Nº6, octubre de 1960, La Plata, p.2 (CPM-DIPPBA, Mesa “A”, Legajo 26)

31 Hacía referencia a los sectores blandos como los jesuitas y bolcheviques con capacidad de ser infiltrados para servir a la coalición de los enemigos duros: masones, judíos y militares liberales golpistas. (Carman, 2015, pág. 376)

$\underline{32}$ En una carta a Perón, del 24 de julio de 1967, Disandro relataba: “... en ocasión de una 
disertación mía sobre la Sinarquía, disertación organizada por la Rama Femenina, pudimos conversar largo y tendido con el mayor Alberte, y convinimos algunos aspectos en la labor de esclarecimiento, aspectos que ya están en marcha. Posteriormente el mayor Alberte, por intermedio del grupo juvenil de la Escuela, organizó en Buenos Aires, en el Sindicato de la Alimentación, la conferencia sobre Brasil, el día 21 de julio de 1967. Esta vez fue un éxito rotundo (...) Creo que puedo dar por terminada esta primera etapa, que ha sido dura y trabajosa. He mantenido reuniones de esclarecimiento y conferencias, sobre los aspectos conversados en Madrid, en Córdoba, La Plata, Buenos Aires, Lanús, Temperley, Quilmes, etc. Le he propuesto al mayor Alberte que haga bajar a Buenos Aires a grupos más o menos diestros de gente que pudiera hacer de repetidores: yo les daría una vez al mes una suscinta preparación sobre uno de los temas candentes, y además les entregaría un epítome o resumen que pueda servirles de guía, o eventualmente que pueda ser reproducido y distribuido. (...) Hay en las bases -tanto políticas como sindicales- un ansia de esclarecimiento; pero también un desconocimiento sobre el actual estado de algunas cuestiones fundamentales. Los enemigos, particularmente el gobierno y otros sectores, en especial vaticanistas, han coaligado sus esfuerzos para DERIVAR EL MOVIMIENTO HACIA OTRAS METAS, como Ud. verá, mi General, por el suscinto informe con que cierro esta carta: (...) Ahora nos pondremos a la tarea de publicar y distribuir la conferencia sobre Brasil, como hicimos con la de Toynbee, que ha tenido gran repercusión. Le he entregado además al mayor Alberte una copia del trabajo sobre la Sinarquía, para que proceda según crea conveniente a su difusión. Me ha prometido reproducirlo y distribuirlo. Por lo común en todas las reuniones la gente inquiere sobre esta cuestión, y muchas veces no hay tiempo de detenerse demasiado.” Extraído de: http://perso.wanadoo.es/prensanacional/perondisandro.htm

$\underline{33}$ En realidad el término sinarquía ya era usado en Francia y en México aunque con un sentido diferente. En Argentina ya lo había mencionado Meinvielle ("La sinarquía: otra empresa de subversión mundial” en Azul y Blanco, año III, Buenos Aires, 5 de mayo de 1959). Sin embargo, fue con Disandro que el término sinarquía adquirió una sistematización, centralidad y difusión de la que carecía antes.

$\underline{34}$ “Estado mundial y destino nacional” en Frontera 67, Año I, No1, enero de 1967, p. 32. (CEDINCI)

$\underline{35}$ Sobre la cultura política de la derecha peronista en la década de 1970 véase (Besoky, 2016b)

$\underline{36}$ El Caudillo de la Tercera Posición, N5, 14 de diciembre de 1973

37 El Caudillo de la Tercera Posición, 30 de octubre de 1975.

$\underline{38}$ “Samoil Cipayosky” en Tacuara. Vocero oficial de la UNES, número 6, año IV, Buenos Aires, octubre de 1948, p. 14.

39 Señala (Senkman, 1986: 133): “En esos días era posible ver algunas calles céntricas de la Capital Federal con pintadas donde se leía: 'FUERA GELBARD JUDIO VENDE PATRIA', 'FUERA JUDIO BOLCHE', 'GELBARD SIONISTA', y otras de la especie.”.

40 El Caudillo, Nº 32 del 21 de junio de 1974.

41 La transcripción del programa fue recopilada en un libro editado por el sello RO.CA. en 1983 
bajo el título Soy fascista ¿y qué? Alberto Ottalagano. Una vida al servicio de la patria.

42 “Cartas al país. Réplica a Ottalagano”, Clarín,3 de septiembre de 1983, p. 14

\section{Referencias bibliográficas}

Axat, J. (19 de 07 de 2011). Poesía y Política. Recuperado el 21 de agosto de 2017, de La historia de Carlos A. Disandro, mentor espiritual de la CNU: http://poesiaypolitica.blogspot.com.ar/2011/07/la-historia-de-carlos-disandro-mentor.html

Beraza, L. F. (2005). Los Nacionalistas. La trayectoria de un grupo polémico (1927-1983). Buenos Aires: Cántaro.

Besoky, J. L. (2016b). "En la patria de Perón, ni judio ni masón" Aproximaciones a la cultura política de la derecha peronista en los años setenta. História e Cultura , 5 (3), 199-223.

Besoky, J. L. (2014). El nacionalismo populista de derecha: La Alianza Libertadora Nacionalista 1937-1975. Mediações , 19 (1), 61-83.

Besoky, J. L. (2013). La derecha peronista en perspectiva. Nuevos Mundos Mundos Nuevos .

Besoky, J. L. (2016a). La derecha también ríe. El humor gráfico en la revista El Caudillo de la Tercera Posición. Tempo \& Argumento , 8 (18), 291-316.

Bohoslavsky, E. (2009). El complot patagónico: nación, conspiracionismo y violencia en el sur de Argentina y Chile siglos XIX y XX. Buenso Aires: Prometeo.

Buchrucker, C. (1987). Los nacionalistas y el peronismo. Buenos Aires: Sudamericana.

Buchrucker, C. (1998). Los nostálgicos del Nuevo Orden y sus vinculaciones con la cultura política argentina. Informe Final de la CEANA, Buenos Aires.

Capizzano, H. M. (2013). Alianza Libertadora Nacionalista: Historia y crónica (1935-1953). Buenos Aires: el autor.

Carman, F. (2015). El poder de la palabra escrita: revistas y periódicos argentinos: 1955-1976. Buenos Aires: Biblioteca Nacional.

Cerrano, C., \& Peñalba, M. (2014). La OMU y la Conferencia Internacional de dirigentes universitarios de junio de 1955 vista desde la delegación española del SEU. Revista electrónica de fuentes y archivos , 5 (5).

Cornejo Linares, J. C. (1964). El nuevo Orden Sionista en la Argentina. Proyecto de investigación de actividades antiargentinas. Buenso Aires: Tacuarí.

Cornejo Linares, J. C. (1966). Política, nacionalismo, estado. Buenos Aires: Cruz y Fierro.

Disandro, C. A. (1973). La conspiración sinárquica y el Estado argentino. Buenos Aires: Independencia y Justicia. 
Duhalde, L. E. (2007). Correspondencia Perón Cooke. Buenos Aires: Colihue.

Furman, R. (2014). Puños y pistolas. Buenos Aires: Sudamericana.

Galván, M. V. (2008). El Movimiento Nacionalista Tacuara y sus agrupaciones derivadas: una aproximación desde la historia cultural. IDAES. Buenos Aires: Universidad Nacional de San Martín.

Goñi, U. (2009). La auténtica Odessa: la fuga nazi a la Argentina. Buenos Aires: Paidós.

Gurucharri, E. (2001). Un militar entre obreros y guerrilleros. Buenos Aires: Colihue.

Hernández, P. J. (2007). Patriotas y patriadas. Buenos Aires: Boquerón.

Jassén, R. (1976). ¡Romper al peronismo!: La doctrina Justicialista, espíritu histórico de Perón. Buenos Aires: Editora de la Reconquista Criolla.

Kilstein, A. (2010). Vínculo entre sectores del peronismo de derecha y la Liga Árabe en la Argentina entre 1962-1964. Segundo Congreso de Estudios sobre el Peronismo 1943-1976. Universidad Nacional de Tres de Febrero.

Kraft, G. (1955). Quién es quién en la Argentina. Biografías contemporáneas. Buenos Aires: Guilermo Kraft Limitada.

Ladeuix, J. I. (2007). El General frente a la Sinarquía. El discurso de Carlos Disandro en la formación de la Concentración Nacionalista Universitaria y su impacto en el peronismo. XI Jornadas Interescuelas / Departamentos de Historia. Tucumán: Universidad Nacional De Tucumán.

Lastra, B. (1944). Bajo el signo nacionalista. Escritos y discursos. Buenos Aires: Alianza.

Lvovich, D. (2006). El nacionalismo de derecha. Buenos Aires: Capital Intelectual.

Lvovich, D. (2009). La extrema derecha en la Argentina posperonista entre la sacristía y la revolución: el caso de Tacuara. Congress of the Latin American Studies Association. Rio de Janeiro.

Lvovich, D. (2003). Nacionalismo y antisemitismo en la Argentina. Buenos Aires: Ediciones B Argentina.

Lvovich, D. (2001). Peronismo y antisemitismo: historia, memorias, mitos. En P. Drieznik, La memoria de las cenizas (págs. 63-76). Buenos Aires: Dirección Nacional de Patrimonio, Museos y Arte.

Perón, J. D. (1968). La hora de los pueblos. Madrid: Norte.

Rein, R. (2015). Entre el peronismo y el nacionalismo de extrema derecha: Jauretche, los argentinos judíos y la acusación de doble lealtad. En G. Marongoni, Pensar Jauretche (págs. 215-238). Unipe.

Rein, R. (2015a). Los muchachos peronistas judíos. Buenos Aires: Sudamericana.

Rock, D. (1993). La Argentina autoritaria. Los nacionalistas, su historia y su influencia en la vida pública. Buenos Aires: Ariel.

Senkman, L. (1986). El antisemitismo en Agentina/1 (Vol. 146). Buenos Aires: Centro Editor de América Latina. 
Senkman, L. (1986). El antisemitismo en Argentina/2 (Vol. 149). Buenos Aires: Centro Editor de América Latina.

Senkman, L. (2001). La derecha y los gobiernos civiles 1955-1976. En R. H. Dolkart (Ed.), La derecha argentina. Nacionalistas, neoliberales, militares y clericales (págs. 275-320). Buenos Aires: Ediciones B .

Senkman, L. (2004). Populismo latinoamericano, etnicidad y organizaciones fascistas: los casos de la AIB brasilera y la ALN argentina. Si somos americanos , 6 (5), 85-106.

Tcach, C. (2001). Los '70: la voz de las consignas. Anuario IEHS: Instituto de Estudios Histórico Sociales (16), 39-57. 